\title{
Research on the Optimization of the Intellectual Property Right Education Based on Cooperation between School and Enterprise
}

\author{
Hong-Zhen LIN $^{1^{*}}$, Feng $\mathrm{YU}^{2}$ \\ ${ }^{1}$ School of Management, Wuhan University of Science and Technology Wuhan, China \\ Distinct addresses: 947 He Ping Street, Hubei Wuhan 430081, China \\ email:linjingziran@126.com \\ ${ }^{2}$ School of Management, Wuhan University of Science and Technology Wuhan, China \\ Distinct addresses: 947 He Ping Street, Hubei Wuhan 430081, China \\ email:2514164870@qq.com \\ Corresponding author: Hong-Zhen LIN
}

\begin{abstract}
Keywords: Cooperation between School and Enterprise, Intellectual Property Education, Teaching Optimization
\end{abstract}

\begin{abstract}
The purpose of this paper is to research ways of the intellectual property right education Based on cooperation between school and enterprise. Using the method of document study and applying theory to practice obtain historical and present related data in order to correctly comprehensively, understand the problem of intellectual property right education. Effective measures and suggestion to promote intellectual property right education should be put forward based on problems. This paper focus on analysis problems and measures of perfecting intellectual property right education. The conclusion is that It is important for school and enterprise to establish the concept of cooperation, to establish long-term cooperation mechanism and to adopt the appropriate teaching model. Effective cooperation between schools and enterprises is helpful to improve the teaching quality of intellectual property.
\end{abstract}

\section{Introduction}

Under the background of the construction of innovative country and the globalization of competition, intellectual property rights have become the core competitiveness of the country and the enterprise. The intellectual property rights have become the important support of the innovative country. Innovation driven development strategy and the construction of intellectual property rights of intellectual property is a huge demand for intellectual property rights and intellectual property personnel training has been unprecedented attention. The colleges and universities should accelerate the cultivation of intellectual property rights.

School and enterprise cooperation is the inevitable choice of the development of the market economy. The school and enterprise cooperation mode is the process of the joint participation of both the school and the enterprise. It has changed the traditional education culture, finding a suitable for enterprise new ways of developing the skills of personnel requirements. The cooperation between schools and enterprises will build a platform for students practice in the enterprises, both an professional knowledge and practical operation skills training while accepting the enterprise culture, professional ethics, professional competency requirements, technical quality standards .[1]

In the industrial technology of collaborative innovation strategy, colleges and universities as one of the most important members should give full play to the role of the strategic cooperation and make clear their own position, to solve the problem of awareness of intellectual property rights and cooperation mechanism. To establish the mechanism of optimization and utilization, the mechanism of cooperation and interaction should be under the national innovation system, and the scientific 
application of market mechanism should be based on the benefit balance mechanism. Colleges and universities should handle the technology of collaborative innovation in the complex relationship between intellectual property rights, use of the intellectual property advantage position, give full play to the advantages of education, to play a leading role of industry technology development and social service function. According to incomplete statistics, the country has set up nearly 50 School of intellectual property rights, more than 60 specialized intellectual property education institutions. ${ }^{[2]}$ Training continues to expand the scale and most take the mode of intellectual property law to train talents in intellectual property. Training has been continuously strengthened. But the reality is that social, especially enterprise is hungry for intellectual property talent. on the other hand, intellectual property professional employment situation is not optimistic. This cannot be no reflection of the traditional intellectual property personnel training model. it need for systematic research and analysis of the problem to explore good training way.

\section{Problems of the Traditional Intellectual Property Teaching Mode \\ First of All, Knowledge Structure is the Bottleneck of Intellectual Property Training at Present.}

Intellectual Property subject is a comprehensive discipline, therefore intellectual property professionals should be proficient in the law, understand the management, familiar with the technology of the composite knowledge structure of talent. And traditional intellectual property talent training model lacks pertinence from the needs of the society. The pure law talent training mode does not conform to the overall characteristics of the field of intellectual property with obvious limitations. It is hard to satisfy the society of knowledge of the structure of complex talent demand. [3]Confined to the cultivation of the lack of talent management, economic or technical background, it is difficult to solve the issue of protection of technological innovation, intellectual property management, and other applications.

\section{Secondly, Occupation Ability is Single and Weakness in Intellectual Property Training.}

Colleges and universities undertake the key ability training of professional ability with the system theory knowledge applied to practice, the ability to solve practical problems. [4]The special nature of intellectual property and talent training is also destined to the university cannot independently enhance and cultivate the intellectual property practical ability .colleges and universities teaching and practice departments disjointed phenomenon still exists, which also in a large extent limiting the training comprehensive quality comprehensively, application type talents of intellectual property.

\section{Finally, the Training Level is A Short Board of Intellectual Property Personnel Training.}

Advance in the process of construction of intellectual power and need different levels of talent requires both to participate in international competition, high-end talents with international vision, also need to adapt to large and medium-sized enterprises in the elite talent, more need to service a large number of small and medium-sized enterprises, solving the practical needs of enterprise service personnel. At present China intellectual property education present single level problem. Better foundation of intellectual property education institutions should pay more attention to intellectual property master, doctor of high-level personnel training. Training scale is still difficult to meet the construction of intellectual power in enterprises, especially large number of small and micro enterprises demand. It is difficult to meet the needs of the society of applied talents. Therefore, it is necessary to adjust the training strength and scale of different levels of talents.

\section{Necessities of Cooperation Training Between School and Enterprise}

First, intellectual property is a intersection of Arts and science, technology and law simultaneously, and both international trade, intelligence, foreign language discipline. However, the 
pure intellectual talent training mode limits the effectiveness of intellectual property personnel training, it cannot reflect the characteristics of intellectual property rights. Therefore, it is necessary to explore and promote the development of intellectual property training in the discipline of integration.

Secondly, intellectual property rights should be proficient in law and understand business management, familiar with the technology of knowledge of the composite structure of talent. Enterprises not only need to focus on the legal protection of intellectual property rights, but also need to focus on technical innovation to protect the practice of intellectual property management and operation of intellectual property rights, which is more reflected in the process of personnel training. ${ }^{[5]}$ And the traditional mode of intellectual property personnel training is generally lack of pertinence from the social reality demand. collaborative training is the requirement of modern educational theory. Co culture is a new type of talents training model.

\section{The Optimization of Collaborative Training between School and Enterprise}

\section{First of All, It is the Foundation of the Cooperative Cultivation of School Subjects.}

The integration of the various relevant departments of the faculty trains students comprehensive ability, to build a scientific, in line with the needs of the community teaching structure. At the same time, implementation "science and engineering undergraduate exemption recommend studying for a master of law in accordance with the undergraduate's academic background as different cultivation objectives, such as the background of law undergraduate students are well versed in the intellectual property practice talent, management or economics background of students to develop good operation of intellectual property management personnel, the engineering background of the students understand the technology with patent talents, and realize the subject blend in the true sense of the students; implementation of intellectual property dual bachelor's degree education, synchronous elective chemical engineering and mechanical engineering etc. According to the demand of the complex knowledge structure of intellectual property talents, the teaching course is set up.

\section{Secondly, the Government, Enterprises, Colleges And Universities Multi Subject Cooperative Training Mechanism Is The Guarantee.}

By strengthening the cooperative training of multiple subjects, it makes it from segmentation to interactive docking. Emphasizing the effective participation of government and society, and realizing the seamless connection between universities and society is important. ${ }^{[6]}$ The government, enterprises, colleges and universities can jointly invest to build research platform and personnel training platform. the government, enterprises, colleges and universities also can participate in the process of intellectual property personnel training.

\section{Third, it is Necessary to Pay Attention to the Order Type Training Mode.}

Students will be the enterprise employees, so school and enterprise management can jointly developed training programs and enterprise technology backbone personnel and professional schools teachers can together complete teaching task targeted training for the demand of enterprise employees. Enterprises according to the demand for human resource allocation plan signed with school "order" training protocol and implementation of tailored to students. In order to Strengthening personnel training target, enterprises and schools should agree to teaching plan, curriculum, practical standards. "Order" form education effectively guarantee the employment of students and make students have the sense of belonging. ${ }^{[7]}$ It makes the teaching more effective, promoting admission to employment and promoting the development of the enrollment pattern. 


\section{Conclusions}

In today's era of the knowledge economy, intellectual property problems become more and more sharp and complex. Therefore, seeking for intellectual property talent cultivation mode of cooperation for the promotion of the collaborative innovation is essential to the healthy development. On the basis for the enterprises to carry out the investigation, universities research cooperate innovation intellectual property of teaching as the breakthrough point based on the characteristics of collaborative innovation of enterprise knowledge property of teaching. School education and business training closely contact. For school and enterprise cooperation of high skilled talents training system, there is a long way to explore. especially under the support of the government, enterprises and schools team up to promote effective cooperation. In the future, we will continue to explore and perfect the mold of school and enterprise cooperation, and strive to expand the team of school and enterprise cooperation, to speed up the training of highly skilled personnel.

\section{Acknowledgement}

This research was financially supported by Hubei Province teaching and research project "Research On The Dynamic Mechanism Of Local Colleges And Universities Service Regional Industry And School Enterprise Collaborative Innovation Talent Training" NO:2013219.

This research was financially supported by Hubei Province Education Department Foundation: Legal Risk And Prevention of University Students' Innovative Undertaking No.201410488028

This research was financially Supported by Wuhan University of Science and Technology course of Quality Course Foundation

\section{References}

[1] Zhong Cantao. University intellectual property management for collaborative innovation [J]. science and technology progress and countermeasures, 2012, 29 (22): 127-131.

[2] Li Yubi, Zhou Yongmei. Research on intellectual property sharing and benefit allocation in collaborative innovation strategy [J]. development and research, 2013 (4): 144-148.

[3] Yang Lingli, Cai Aihui, Yang Chaohua. Research on effective cooperation mechanism of intellectual property in Universities under cooperative innovation mode [J]. science and technology progress and countermeasures, 2012, 29 (22): 134-136.

[4] Chen Yuan. Research on intellectual property protection of students in Higher Vocational Colleges -- a case study of school enterprise cooperation personnel training model [J]. theory, 2013 (35): 230-231.

[5] Gu Xiaoyan. Research on the training mode of intellectual property in Universities under the background of the implementation of innovation driven strategy [J]. statistics and management, 2014 (8): 108-110.

[6] Zhang Tirui. Intellectual property law teaching reform ideas: [J]. science guide and version, 2014 (28): 124-125.

[7] Shen Shijuan. Teaching innovation practice of intellectual property law [J]. Journal of Jiangsu Teacher University of Technology, 2014, 20 (1): 109-110. 